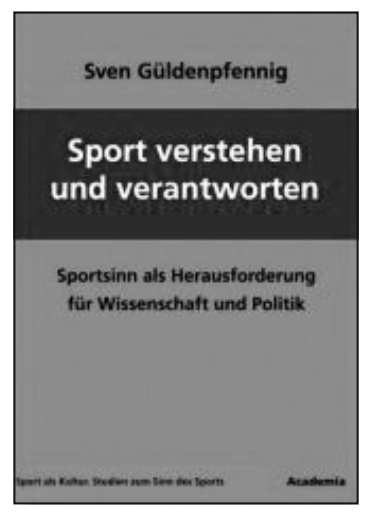

SVEN GÜLDENPFENNIG:

\title{
Sport verstehen und verantworten
}

Sportsinn als Herausforderung für

Wissenschaft und Politik

(Sport als Kultur. Studien zum Sinn des Sports)

St. Augustin: Academia, 2007. 354 S.; € 32,-

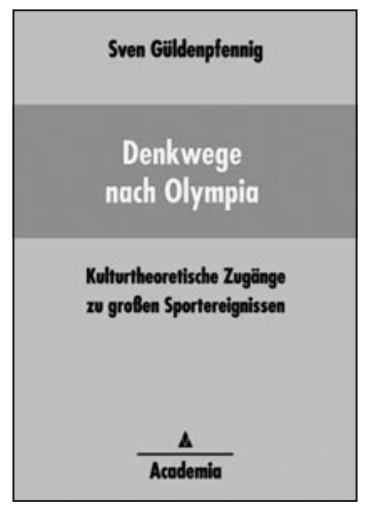

SVEN GÜLDENPFENNIG:

\section{Denkwege nach Olympia}

Kulturtheoretische Zugänge
zu großen Sportereignissen

St. Augustin: Academia, 2006. 312 S.; € 32,-

Die deutsche Sportwissenschaft begreift sich als interdisziplinäre Wissenschaft. Sie bemüht sich, Erkenntnisse aus den jeweiligen Mutterwissenschaften $\mathrm{zu}$ reflektieren und nutzbar zu machen. In diesem interdisziplinären Selbstverständnis liegt jedoch ein Problem des Faches begründet. Bei aller wünschenswerten Multiperspektivität des Erkenntnisinteresses verschwimmt infolge dieses Anspruchs oftmals genau das, was das Eigentliche der Sportwissenschaft auszeichnet, eine klare Bestimmung dessen, was Sport als Gegenstand wissenschaftlichen Interesses definiert. Der Sportwissenschaft fehlt eine Klammer, die die subdisziplinären Erkenntnisse unter einem gemeinsamen sportlichen Erkenntnisinteresse zusam- menfasst. Die Suche nach einer solchen Klammer der Sportwissenschaft kann als Leitmotiv der hier vorgestellten Publikationen gedeutet werden.

Sven GÜLDENPFENNIG orientiert sich in seinen jüngeren Veröffentlichungen nicht nur in der Art und Weise der wissenschaftlichen Annäherung an sein Objekt, sondern auch stilistisch weniger an sportwissenschaftlichen Arbeiten, sondern findet Vorbilder und Denkanstöße eher in den Geisteswissenschaften, respektive dem Feuilleton der relevanten deutschsprachigen Printmedien (vgl. u. a. GÜLDENPFENNIG, 2007, S. 151153). Wenngleich der Sport mittlerweile ein gern gesehener Gast im Bereich des hermeneutischen Diskurses ist und sich immer mehr Intellektuelle mit der 